\title{
BOAR VESICULAR SECRETION PROTEINS: FURTHER COMPARISONS WITH SEMINAL PLASMA PROTEINS
}

\author{
J. C. BOURSNELL, P. A. BRIGGS ANd D. M. COLE \\ A.R.C. Unit of Reproductive Physiology and Biochemistry, Cambridge*
}

(Received 25th November 1967)

\begin{abstract}
Summary. Further studies, using gel filtration on Sephadex G-200 columns, have confirmed and extended the similarities between the major proteins of boar seminal plasma and the vesicular secretion.

The haemagglutinin in the vesicular secretion has been shown, by red cell agglutination, to occur as a distinct peak masked by the greater protein content of Fraction A.

Completely fresh vesicular secretion kept at $37^{\circ} \mathrm{C}$ and studied at this temperature within $30 \mathrm{~min}$ of slaughter, presents an identical gel filtration pattern.
\end{abstract}

\section{INTRODUCTION}

Evidence described in previous papers (Nelson \& Boursnell, 1966) has been accumulated about the properties and behaviour of the protein components of boar seminal plasma. Two of the proteins (Fractions A and B) appear to comprise about $98 \%$ of the total. It has been shown (Boursnell \& Coombs, 1966) that a third protein is present which has powerful haemagglutinating properties and also clumps foreign spermatozoa in a tail-to-tail agglutination (Boursnell, 1967). It appears that this protein (or proteins) possesses considerable basic properties, apparently combining with and precipitating the Fraction B protein in low salt concentrations (values of ionic strength $(I)$ between 0.15 and 0 ).

Boursnell, Johnson \& Zamora (1962) showed that there appeared to be close electrophoretic similarity between the major proteins occurring in boar seminal plasma and those in the vesicular secretion from which they have arisen. They also showed that vesicular secretion was coagulable by heat and partially precipitable by dilution with an equal quantity of water and by $12 \%$ (w/v) $\mathrm{Na}_{2} \mathrm{SO}_{4}$, properties closely resembling those of seminal plasma.

Boursnell \& Coombs (1966) showed that the agglutinin, whose presence they demonstrated in seminal plasma, also originated in the vesicular secretion. Other properties of the agglutinin have been investigated and are described in this paper. These properties further serve to underline similarities between seminal plasma proteins and those of the vesicular secretion.

* Postal address: Animal Research Station, 307 Huntingdon Road, Cambridge. 


\section{METHODS}

Boar semen was obtained from animals housed at the Animal Research Station by the use of artificial vaginae. The gel was removed immediately by filtration through muslin and the spermatozoa were removed by centrifuging at $10,000 \mathrm{~g}$ at $4^{\circ} \mathrm{C}$. The supernatant fluid, that is the seminal plasma, was stored at $-20^{\circ} \mathrm{C}$ until required.

Vesicular secretion was obtained, except in one case described, by dissection of the seminal vesicles from fresh slaughterhouse material. The glands, placed in a large funnel, were allowed to drain naturally. The resulting fluid was centrifuged at about $1000 \mathrm{~g}$ and the supernatant fluid stored at $-20^{\circ} \mathrm{C}$.

Sephadex G-200 columns (Pharmacia (Great Britain) Ltd) were prepared and used as described by Boursnell, Nelson \& Cole (1966) except where otherwise indicated. Column fractionation was normally carried out at room temperature (about $19^{\circ} \mathrm{C}$ ).

Haemagglutinating activity was determined by doubling dilution as described by Boursnell (1967), using a washed sheep erythrocyte suspension in normal saline. The results were expressed either in terms of the titre (e.g. $2,4,8, \ldots, 256,512$, etc.) or merely as the number of the last tube exhibiting agglutination (e.g. 1, 2, 3, . , 8, 9, etc.).

Protein was determined by the Lowry, Rosebrough, Farr \& Randall (1951) modification of the Folin-Ciocalteu method. Protein standard curves were prepared from chicken ovalbumin.

\section{RESULTS}

Values of $p H$ and I causing precipitation of boar vesicular secretion proteins

If a 'grid' is prepared, showing the qualitative degree of precipitation of seminal plasma proteins at various values of $\mathrm{pH}$ (ordinate) and $I$ (abcissa), it is clear (Bennett, 1965) that boar seminal plasma, largely because of the relatively high isoelectric point of component $A$, behaves very differently from the seminal plasmas of bull, ram or rabbit. A similarly prepared grid investigating boar vesicular secretion shows a precipitation pattern identical to that of boar seminal plasma.

\section{Behaviour of boar vesicular secretion on Sephadex $G-200$ gel filtration}

Text-fig. 1 shows the protein pattern at $\mathrm{pH} 4 ; I=0.3$ upon elution at room temperature of a sample of vesicular secretion. Substantially, Fractions $A$ and $B$ are identical in shape and position to those given by the seminal plasmas reported by Boursnell et al. (1966). Studies at $I=0.3$ but at different pH values, namely from 3.0 to 10.0 , showed little change from Text-fig. 1 except that at higher $\mathrm{pH}$ values ( 7 to 9 ) the relative size of the Fraction $\mathrm{A}$ peak lessened. This could be due to its partial precipitation even at $I=0.3$ at or near the isoelectric point (Boursnell et al., 1962).

Determination of the haemagglutinating fastor in Sephadex $G-200$ fractions

Observations at $\mathrm{pH} 4 ; I=0.3$ were made upon the distribution of the haemagglutinin titre in the vesicular secretion fractions collected under normal 
conditions at room temperature (Text-fig. 1). Other observations at $I=0.3$ and at $\mathrm{pH}$ values from 3.0 to 10.0 inclusive showed a very similar distribution at all values. An identical distribution of the haemagglutinating factor was established with seminal plasma.

It was also established that, at $\mathrm{pH} 4$, values of $I$ from 0.1 to 0.5 caused no significant change in the gel filtration pattern of vesicular secretion.

The ratio: haemagglutinin titre (tube number) to protein $O D$ value was calculated and plotted on the corresponding protein curves for each $\mathrm{pH}$. Although in some cases the maximum ratio occurred at the lowest part of the valley, more frequently it corresponded to the position of the maximum haemagglutinating titre. There was no significant change from this pattern at any $\mathrm{pH}$ value between 3 and 10 .

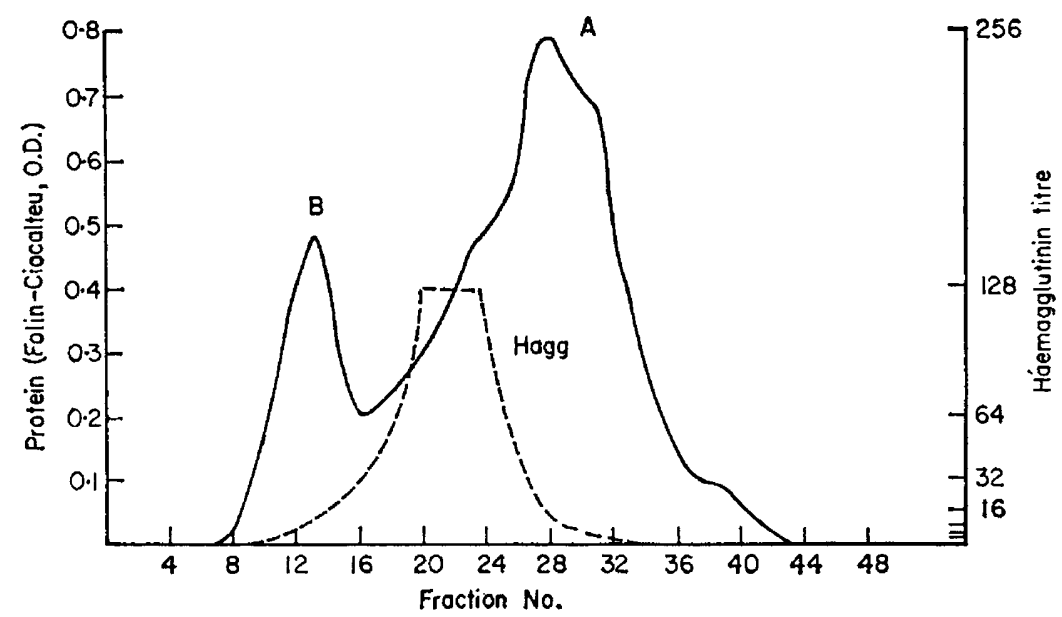

TEXT-FIG. 1. Diagram of protein (- $\longrightarrow$ ) and haemagglutinin titre (- . - . - ) in eluates from Sephadex G-200 gel filtration of boar vesicular secretion at $\mathrm{pH} 4 ; I=0.3$. A, Fraction A peak; B, Fraction B peak; Hagg, haemagglutinin titre. The probable error (one tube) in the determination of the titre will alter greatly the shape of the haemagglutinin curve, especially at the 'peak' where the influence of this error is greatest. Mathematical analysis shows that, if the haemagglutinating protein does occur as a Gaussian curve, the representation of this by the haemagglutinin reaction using a doubling dilution titration as above, will give a peak which is flattened at the top.

Effect of dialysis at $I=0.015$ of boar vesicular secretion

Investigation, using the conditions described (Boursnell \& Nelson, 1965) for seminal plasma, showed that a precipitate (B Dial) occurred also on dialysing vesicular secretion at $\mathrm{pH} 8.0 ; I=0.015$. Elution on a Sephadex G-200 column of the proteins comprising the supernatant (A Dial) and precipitate showed that, as with seminal plasma, an almost complete separation of Fractions A and B had been achieved.

\section{The effect of glycine on the Sephadex column fractionation}

To determine whether glycine, which temporarily inhibits the precipitation of Fraction B by Fraction A (Nelson \& Boursnell, 1966), causes any change in the Sephadex pattern, a buffer of $\mathrm{pH} 4 ; I=0.3$ containing 0.2 m-glycine was 
used to equilibrate the gel and to develop the column. The result was, however, similar in every respect to the pattern obtained without glycine.

Sephadex $G-200$ fractionation at $37^{\circ} \mathrm{C}$ of fresh vesicular secretion

Seminal vesicles were excised from a boar immediately after slaughter and placed in a polythene bag which was immersed in water at $37^{\circ} \mathrm{C}$. The secretion obtained after rapid dissection was quickly placed, within $15 \mathrm{~min}$ of slaughter, on a water-jacketed column maintained at $37^{\circ} \mathrm{C}$ and developed with a $\mathrm{pH} 4$; $I=0.3$ buffer also at this temperature. Although at no time did the temperature of the glands or their secretion fall significantly, the Sephadex G-200 pattern distribution of Fraction A and B and the basic haemagglutinins were identical with that of the frozen material depicted in Text-fig. 1. The initial fresh warm vesicular secretion had a haemagglutinating titre of 32,000. Tests showed that a separate sample obtained by squeezing the dissected glands at the end of the draining had an identical titre.

\section{DISGUSSION}

Further gel filtration studies have shown that the distribution of the haemagglutinating proteins in the Sephadex G-200 fractions exhibits a peak which is remarkably constant over a considerable range of $\mathrm{pH}$ and ionic strengths. The haemagglutinin first appears in the Sephadex fractions at the beginning of the Fraction B peak. From thence it increases to a maximum at the beginning of of the Fraction A peak, just after the minimum protein value between the two peaks A and B. In all cases the titre under the Fraction B peak was much less than that contained within the Fraction A peak. The final disappearance of haemagglutinating activity in the column fractions occurs well within the Fraction A peak and the low molecular weight end of Fraction A is usually free of haemagglutinin.

In Text-fig. 1 the haemagglutinin peak is plotted on a scale representing the titre of the particular fraction. It must be emphasized that, of necessity, the scale of the haemagglutinin peak bears no relation to the scale representing Fractions A and B protein. The amount, in terms of protein, of the haemagglutinin is not at present known and generally does not appear as a distinct protein peak when determined by the Folin-Ciocalteu method. A shoulder sometimes appears on the high molecular weight side of the Fraction A peak and a possible connection between this and the presence of the haemagglutinating peak is being investigated.

Earlier studies on this distribution were carried out on seminal plasma samples which had been frozen soon after collection and separation from the spermatozoa. It seemed possible that a different pattern might be observed in vesicular secretion: however, again, with frozen fresh slaughterhouse material, an apparently identical distribution was observed. This suggests either that the distribution pattern may already be fixed in its observable form when the material is secreted from the glands or that subsequent cooling and storage influence the distribution. In order to study these alternatives especial care was taken to obtain a completely fresh uncooled sample of vesicular secretion which 
was studied in a $37^{\circ} \mathrm{C}$. Sephadex G-200 column within a few minutes of the slaughter of the boar. Again no differences were evident even at this early stage. This would suggest that the haemagglutinin distribution given by Sephadex G-200 at room temperature is not influenced to any great extent by prior cooling and freezing. It would seem from these results that the other secretions present in seminal plasma (from the prostate, Cowper's glands, epididymides, etc.) also have little or no influence. The viscosity of freshly collected vesicular secretion does increase rapidly, however, and this phenomenon is being studied in an effort to elucidate further the whole pattern of events occurring during ejaculation.

The occurrence of a higher haemagglutinating titre in the first part of the Fraction A peak helps to explain the phenomenon observed by Nelson \& Boursnell (1966) that, while Fraction B obtained from the Sephadex column does not precipitate at low ionic strength it does so upon the addition of an aliquot of Fraction A. This addition would increase the basic haemagglutin content of the mixture, possibly promoting the precipitation observed at lower ionic strengths.

\section{AGKNOWLEDGMENTS}

We would like to express our thanks to Dr C. Polge for numerous boar semen collections; to Mr L. E. A. Rowson for excising the seminal vesicles under warm conditions; to $\mathrm{Mr} \mathbf{H}$. C. Toates for frequent collections of citrated blood from the abattoir. In particular our thanks are due to $\mathrm{Mr} \mathrm{A}$. D. Burgen, who assisted us with many experiments during one summer vacation.

\section{REFERENCES}

BenNETT, J. P. (1965) Quantitative comparisons of the proteins of the seminal plasmas of bull, ram, rabbit and boar by agar gel electrophoresis. F. Reprod. Fert. 9, 217.

Boursnely, J. C. (1967) Boar seminal haemagglutinin. II. Combination with red cells and spermatozoa. 7. Reprod. Fert. 13, 297.

Boursnell, J. C. \& Coombs, R. R. A. (1966) A haemagglutinating factor in boar seminal plasma. 7. Reprod. Fert. 11, 139.

Boursnell, J. C., Johnson, P. \& Zamora, J. (1962) An electrophoretic and ultracentrifugal study of boar seminal plasma. Biochim. biophys. Acta, 63, 374.

Boursnell, J. C. \& Nelson, M. (1965) Studies on boar seminal plasma proteins. 2. An investigation on the heat-coagulable component ("Fraction A"). Biochim. biophys. Acta, 104, 181.

Boursnell, J. G., Nelson, M. \& Cole, D. M. (1966) Studies on boar seminal plasma proteins. 3. Fractionation by gel filtration, ion exchange and other means. Biochim. biophys. Acta, 117, 134.

Lowry, O. H., Rosebrough, N. J., FARR, A. L. \& Randall, R. J. (1951) Protein measurement with the Folin phenol reagent. F. biol. Chem. 193, 265.

Nelson, M. \& Boursnell, J. C. (1966) Studies on boar seminal plasma proteins. 4. Isolation of factors with haemagglutinating and protein-precipitating activity. Biochim. biophys. Acta, 117, 144. 